\title{
XIII INTERNATIONAL LEPROSY CONGRESS, THE HAGUE, NETHERLANDS 11-17 SEPTEMBER 1988
}

\section{Editorial}

The XIII International Leprosy Congress, organized under the joint sponsorship of the International Leprosy Association and the World Health Organization, was held in the Congress Centre, The Hague, from 11-17 September 1988. It was attended by over 1200 delegates from more than 100 different countries, including all those where leprosy is endemic and, as on previous occasions, the original papers, poster presentations, exhibits and keynote speeches covered the entire subject of leprosy in all its aspects. The 5 plenary sessions, with keynote or 'state of the art' lectures, covered Immunological tools for leprosy control (P E M Fine, UK); Recent developments in molecular biology (B R Bloom, USA); Operational aspects of multidrug therapy (M Becx-Bleumink, Netherlands); Nerve damage (C K Job, USA); Training and social aspects (L B Valencia, Philippines). These early morning lectures were extremely well attended and generally much appreciated. Paul Fine reviewed the immunological tools which are under development and Barry Bloom the current work and advances in molecular biology, both in masterly fashion, but both drew attention, in their concluding remarks, to the gulf between research potential on the one hand, and actual availability for operational use on the other. Marijke Becx-Bleumink's review of operational aspects was warmly received by a packed house; her observations, largely based on experience in the Shoa Province of Ethiopia, were at the same time critical, stimulating and encouraging. She drew attention to the established effectiveness of multiple drug therapy as advised by the World Health Organization, and to the progress which has so far been made in many countries in implementation, whilst at the same time discussing the lack of progress, amounting in some cases almost to 'stagnation', in others. Indeed, the whole subject of the impediments at operational level to the faster and wider implementation of multiple drug therapy, soon became one of the outstanding topics for discussion at this Congress. Professor Job described the histopathological changes occurring in the nerves of patients with different forms of leprosy with a professionalism which can only come from life-time study, and emphasized our continuing ignorance about the basic mechanisms involved and the sad effect this has on our ability to predict and prevent nerve damage at clinical level. Lastly, Professor Valencia from the Philippines drew attention to the poor performance of social science to date, in the collection of reasonably objective data using proved methods in sociology, anthropology and psychology, to produce findings of practical importance in leprosy control.

From these absorbing and at times exciting sessions, the delegates (after pausing for a cup of coffee and the usual quick discussion or exchange of views on matters which sometimes turn out to have far-reaching importance at such international meetings), moved to the various floors and lecture rooms of the vast Congress Centre to oral or poster presentations on: clinical aspects; immunology; treatment; microbiology; surgery and rehabilitation; ophthalmology; nerve damage; experimental leprosy; epidemiology; experimental therapy; pathology; training and social aspects. 
It was clear from this Congress that mycobacterial diseases in general and leprosy in particular, are far from being left behind with regard to the application of recent advances in immunology, microbiology and molecular biology. Unfortunately, conflicting simultaneous sessions made it impossible for those interested in these aspects to hear much of what was presented. While such conflicts are inevitable at large international meetings of this type, perhaps more thought should be given in future to the scheduling of these sessions.

An area which has clearly been the focus of much attention over the last few years has been the use of our increasing knowledge of the detailed immunochemistry of mycobacteria to develop seroimmunological tools for diagnosis and epidemiology. Methods based on the detection of antibodies or antigens in body fluids or tissues were presented by many groups. While, as Paul Fine pointed out in his keynote address, the value of these techniques at the operational level is questionable, we have learned much about the immune response to Mycobacterium leprae from these studies, and new approaches presented at the Congress hold out much promise.

Leprosy is at the forefront of research in cellular immunology and this was reflected in the high quality of papers presented at the Congress. Convincing evidence for the presence of $\mathrm{T}$ suppressor cells (a subject of much heated debate among cellular immunologists) was presented, and new techniques for defining the antigens recognized by $\mathrm{T}$ cells (pioneered by leprosy research) are being used. In addition, much attention has centred on investigating $T$ cell responses to those antigens which have been expressed by recombinant DNA technology, though there is little evidence, as yet, for their role in protective immunity. New evidence that $M$. leprae cell walls contain major immunogenic proteins provides a new lead to our understanding of the way in which M. leprae is recognized by the immune system.

The application of molecular biology to our understanding of leprosy and its causative organism has got underway during the last 5 years, with the cloning and expression of a number of $M$. leprae genes in $E$. coli, detailed studies of the nucleic acids of $M$. leprae and the development of mycobacterial genetics. This work was well represented during the Congress and holds out much promise for unravelling the complex interaction between host and pathogen. Preliminary evidence which was presented suggests that it might be possible to detect strain differences between $M$. leprae isolates, based on readily detectable differences between nucleic acid sequences, which could have important application in epidemiological studies. In addition, methods for studying the expression of mycobacterial genes and for transferring genes between mycobacteria could lead to important developments in the diagnosis of mycobacteriosis; further cloning of immunologically important molecules and enzyme targets for drugs; understanding the basic mechanisms involved in pathogenicity and for vaccine development.

Impressive progress in the area of experimental chemotherapy was presented. Although this field has taken something of a back seat in recent years, reports of new drugs, some belonging to totally new classes of compounds, and new methods for assessing drug activity were reported, which gave an air of unexpected excitement to these sessions.

With regard to the remaining subjects, including clinical and social aspects and the other less 'scientific' disciplines, the very number and diversity of them defies summary. But, in both oral and poster media, there were excellent contributions from all over the world, accompanied by lively discussion. It is, however, difficult to escape the comment that presentation could be improved; many of the transparencies projected during oral sessions were faded, illegible or crowded with indigestible detail. Several poster presentations had obviously been prepared at the last minute using rough sheets of paper and a felt pen, and the lighting in the poster area was generally substandard. It should not be beyond us to set minimum standards of presentation and to demand that they are respected.

Elsewhere in this Journal we publish accounts of the Pre-Congress Workshops which give some idea of current thinking on many aspects of leprosy. The Abstracts, thanks to a most generous and thoughtful initiative by the Associazione Italiana 'Amici di R. Follereau' were presented to each delegate on arrival. There were also teaching and training sessions on leprosy immunology; 
epidemiology and control; the design and implementation of a leprosy information system; the pathophysiology of nerve damage; the assessment of management of neuropathic limbs; chemotherapy in leprosy; histopathological diagnosis of leprosy; how to diagnose and classify patients; leprosy control- educating community and patients; the eye in leprosy; recognition and management of reactive phenomena in leprosy. The organizers also provided excellent facilities for a number of stalls and exhibits, some of them for commercial companies, others for independent agencies dealing with teaching and learning materials in leprosy (TALMILEP), aids for the disabled (WLEREC and Modulan), and coordination (ILEP, International Federation of Anti-Leprosy Associations).

Can the general impact of such a momentous and wide-ranging Congress be summarized? Probably not. But one thing is clear-progress is being made. Multiple drug therapy, notably in the form recommended by the World Health Organization in 1982, is effective and available. The pace of implementation is improving, although there are grounds for believing that it should be faster and wider (many aspects of this vitally important subject were discussed at the WHO Third Coordinating Meeting on Implementation of Multidrug Therapy in Leprosy Control during the Congress and the conclusions will be circulated at a later date). Immunological tools and vaccines are not yet available and 'established', but remarkable progress is being made and in the next few years it is possible that they will be in use at operational level. There is an awareness that our knowledge of the mechanisms involved in nerve damage, notably in relation to reversal (upgrading) reactions is defective and that it calls, almost as a matter of urgency, for further study.

At the Opening Ceremony, a beautifully made film from WHO carried the title 'Multidrug Therapy for Leprosy: an End in Sight'. There is much to be done and we should not underestimate the magnitude of the task ahead, but the main message from this historic Congress in The Hague is that we can now control and perhaps eventually eradicate this disease.

Slade Hospital,

Headington, Oxford $\mathrm{OX} 37 \mathrm{JH}$

A C MCDOUGALL

National Institute for Medical Research,

M J COLSTON

Mill Hill,

London NW7 IAA 